\title{
OS MOMENTOS DA AÇÃO E AS SITUAÇÕES JURÍDICAS NO PROCESSO: UMA PROPOSTA DE CONVERGÊNCIA DAS TEORIAS DE GREGORIO ROBLES E JAMES GOLDSCHMIDT ${ }^{1}$
}

\author{
MOMENTS OF THE LEGAL ACTION AND JUDICIAL SITUATIONS IN THE \\ LEGAL PROCESS: BRINGING TOGETHER THE THEORIES OF GREGORIO \\ ROBLES AND JAMES GOLDSCHMIDT
}

Mantovanni Colares Cavalcante

Doutor pela Pontifícia Universidade Católica de São Paulo (PUC/SP). Mestre pela Universidade Federal do Ceará (UFC). Membro do Instituto Brasileiro de Direito Processual (IBDP). Professor de Direito Processual da Universidade Federal do Ceará (UFC). Professor Conferencista de Direito Processual Tributário do Instituto Brasileiro de Estudos Tributários (IBET). Juiz de Direito de Vara da Fazenda Pública. Fortaleza/CE. E-mail: mantovanni@ufc.br

RESUMO: Ao discorrer acerca do fenômeno da ação no direito processual, Gregorio Robles traz um ponto de vista inédito, enfatizando que a teoria da ação se concentrou exclusivamente na ação processual, ou seja, somente no início da atividade jurisdicional, quando o tema é muito mais amplo. Antes mesmo dos anos trinta do século passado, James Goldschmidt defendia que os direitos e obrigações, no âmbito do processo judicial, deveriam ser substituídos pelas expectativas, possibilidades e ônus, integrantes de uma situação de direito. Assim, no processo, o que se tem são situações jurídicas, ao invés de uma relação jurídica. Goldschmidt abandonou a visão estática do direito processual, para adotar uma perspectiva dinâmica, da mesma maneira como Gregorio Robles o fez quanto ao fenômeno da ação. Desse modo, é possível realizar

\footnotetext{
${ }^{1}$ Artigo recebido em 18/11/2021 e aprovado em 03/12/2021.
} 
uma convergência dessas teorias e estabelecer algumas das situações jurídicas produzidas em diversos momentos da ação no processo judicial.

PALAVRAS-CHAVE: Direito; processo; ação; relação jurídica; situação jurídica.

ABSTRACT: When addressing the action phenomenon in procedural law, Gregorio Robles provides a unique point of view, by emphasizing that the action theory has been focused solely on the procedural action, that is, only at the beginning of judicial activity, whereas the theme is a lot broader. And even before the last century 30s, James Goldschmidt used to argue that the rights and duties under the judicial process should be replaced by the expectations, possibilities, and burdens, which are present in a legal situation. Thus, in the legal process, there are legal situations, rather than a judicial relationship. Goldschmidt abandoned the static view of procedural law to adopt a dynamic perspective of the legal process, just as Gregorio Robles did concerning the action phenomenon. Therefore, it seems interesting to bring these theories together to establish some of the judicial situations produced at several moments of the action in the legal process.

KEYWORDS: Law; legal process; legal action; judicial relationship; judicial situation.

“- Olha lá, oh amigo! Aí se descobre a cidade, castelo ou fortaleza onde deve de estar algum cavaleiro oprimido, ou alguma rainha, infanta ou princesa malparada, para cujo socorro aqui fui trazido.

- Que diabo de cidade, fortaleza ou castelo é esse que vossa mercê diz, senhor? - disse Sancho. - Não vê que aquelas são azenhas postas no rio, onde se mói o trigo?

- Cala-te, Sancho - disse D. Quixote -, pois ainda que pareçam azenhas não o são, e já te disse que todas as coisas os encantamentos mudam e transtornam do seu natural. Não quero dizer que as mudem realmente de um em outro ser, senão que assim parece (...)"2.

\footnotetext{
2 “- ¿Vees? Allí, joh amigo!, se descubre la ciudad, castillo o fortaleza donde debe estar algún caballero oprimido, o alguna reina, infanta o princesa malparada, para cuyo socorro soy aquí traído.

- ¿Qué diablos de ciudad, fortaleza o castillo dice vuesa merced, señor? - dijo Sancho - ¿No echa de ver que aquellas son aceñas que están en el río, donde se muele el trigo?
} 
(O Engenhoso Cavaleiro D. Quixote de la Mancha. Segundo Livro. Tradução de Sérgio Molina. Capítulo XXIX. São Paulo: Editora 34, 2007. pp. 365/366)

\section{INTRODUÇÃ̃O}

É possível que se indague qual o sentido de agregar duas teorias tão separadas no tempo e pelo espaço - termo aqui utilizado dentro de uma divisão do Direito em suas categorias, no caso, Direito Processual e Teoria do Direito -, considerando a modernidade a impor soluções práticas para tantos problemas a surgir diariamente na jurisdição.

Exatamente aí reside, a meu sentir, o equívoco no enfrentamento dos entraves nos litígios submetidos à jurisdição. Tenho afirmado reiteradamente que todo problema jurídico é consequência de alguma falha teórica. Isso se aplica, por óbvio, ao Direito Processual.

A Teoria do Direito Processual - praticamente firmada na doutrina pela expressão Teoria do Processo - não só se mostra relevante para as questões práticas, na verdade, diria que é fundamental.

Basta citar um exemplo a respeito das condições da ação, pois esses pressupostos foram construídos ao longo do desenvolvimento da ciência do Direito Processual, mas no anseio de se desvencilhar de tantas análises sobre as teorias da ação ${ }^{3}$, o Código de Processo Civil optou por dizer que, com o protocolo da petição inicial, considera-se proposta a ação ${ }^{4}$. É como se, num passe de mágica, as condições da ação fossem evaporadas pela varinha de condão do pragmatismo, refletido num ato mecânico ou eletrônico: o protocolo.

\footnotetext{
- Calla, Sancho - dijo don Quijote -, que aunque parecen aceñas no lo son, y ya te he dicho que todas las cosas trastruecan y mudan de su ser natural los encantos. No quiero decir que las mudan de en uno en otro ser realmente, sino que lo parece (...)”. Ob. cit., pp. 365/366. A edição é bilíngue.

${ }^{3}$ A título de sugestão para o exame da evolução e das muitas questões ainda importantes para o estudo sobre os desdobramentos das teorias da ação, indico a coletânea de textos organizada por Fábio Cardoso Machado e Guilherme Rizzo Amaral, Polêmica sobre a ação - a tutela jurisdicional na perspectiva das relações entre direito e processo. Porto Alegre: Livraria do Advogado. 2006.

${ }^{4}$ Código de Processo Civil de 2015: “Art. 312. Considera-se proposta a ação quando a petição inicial for protocolada, todavia, a propositura da ação só produz quanto ao réu os efeitos mencionados no art. 240 depois que for validamente citado.
} 
Todavia, a realidade está a gritar em outra norma, a que diz, nesse mesmo Código, que "para postular em juízo é necessário ter interesse e legitimidade” (art. 17).

Eis as condições da ação de volta. Uma questão teórica, que não pode deixar de ser considerada; afinal, como dizer que uma ação é proposta sem a análise desses requisitos? Então alguém sem legitimidade, ao protocolar uma petição inicial, pode afirmar que se tem naquele instante a ação? Absolutamente equivocada tal assertiva. $\mathrm{O}$ protocolo faz surgir o processo; a ação dependerá do exame de seus pressupostos ou condições.

O próprio art. 312 do Código de Processo Civil de 2015, que se anuncia como a varinha de condão, está inserido no Título I (Da Formação do Processo) do Livro VI (Da Formação, da Suspensão e da Extinção do Processo) da Parte Geral do Código. Ou seja, ali a normatização é toda sobre processo. Quem cuida da ação é justamente o Título I (Da Jurisdição e da Ação) do Livro II (Da Função Jurisdicional) da Parte Geral do Código.

Por isso, as teorias não só merecem como devem ser revisitadas, e aqui se fará justamente uma abordagem de duas delas, extremamente relevantes para o Direito, a fim de se estabelecer uma convergência para um propósito, a ser identificado mais adiante.

\section{A PERPLEXIDADE COMO PERSPECTIVA E O PERCURSO DA INTERPRETAÇÃO}

O destaque literário no início deste artigo é de um trecho pouco lembrado da magistral obra de Miguel de Cervantes. Ao invés da clássica cena do ataque aos moinhos de vento, essa passagem nos mostra o momento da maturidade do Senhor Quixote da Mancha, por ter a consciência de que sua imaginação é capaz de criar cenários e situações desfocadas da realidade.

Quixote, ali, tem a exata noção da realidade. Ainda assim nos mostra ser correto insistir nos sonhos; afinal, não se pode mudar as coisas, mas é possível interpretá-las.

No início da particular cruzada da personagem, tendo por fiel escudeiro o cético Sancho, os moinhos eram gigantes, e disso o delirante sonhador não tinha dúvida, 
porque somente assim se justificaria seu combate às injustiças e a proteção aos desamparados.

Após tantas caminhadas, o Cavaleiro da Triste Figura finalmente é capaz de compreender que as azenhas - moinhos movidos a água - são simplesmente azenhas. Todavia, ele prefere vê-las como cidade, castelo ou fortaleza, com pessoas à espera de sua ajuda, e isso o torna feliz, pois o que de fato importa é o sentido que ele atribuiu às coisas.

Interpretar é atribuir sentido ao objeto examinado, essa é a lição. E, para que se impulsione a intepretação, muitas vezes é preciso o espanto. Eis a chave libertadora para a observação de determinado objeto noutra perspectiva: a da perplexidade. A partir dela, elaboram-se conclusões não imaginadas em momento anterior a esse giro visual.

O espanto, e depois a interpretação, esse é o percurso gerador de sentido para fixar a compreensão. Embora isso nem sempre ocorra dessa maneira, ou seja, não se tem aí um trajeto obrigatório - do espanto à atribuição de sentido -, mas quando acontece, é algo muito enriquecedor.

Um dos episódios envolvendo essa perplexidade, se deu por ocasião da leitura de um pensamento de Gregorio Robles, segundo o qual "a teoria do direito vem sendo desidiosa no tratamento da teoria da ação" e, segundo o Jurista, esse descuido estaria também presente no Direito Processual, pois o estudo daquele tópico se concentrou na ação processual quando, na verdade, tal fenômeno representaria unicamente o início da atividade jurisdicional, não esgotando o tema da ação ${ }^{6}$.

Desde então, passei a meditar a respeito dessa observação quanto à ação judicial, pois não recordava ter visto algo tão provocativo no enfoque do Direito Processual ${ }^{7}$.

\footnotetext{
${ }^{5}$ O Direito como Texto: Quatro Estudos de Teoria Comunicacional do Direito. Tradução de Roberto Barbosa Alves. Barueri, SP: Manole, 2005. p. 38.

${ }^{6}$ Ob. cit., p. 39.

7 Tais reflexões resultaram na realização da palestra com o título Moments of legal action in procedural law and some judicial situations produced in the legal process: bringing together the theories of Gregorio Robles and James Goldschmidt, na Georgetown University, em Washington D.C., no XXVII World Congress of the International Association for the Philosophy of Law and Social Philosophy, em julho de 2015. O presente texto é um desdobramento dessa palestra e dos debates que ali ocorreram, possibilitando o aprofundamento do tema.
} 


\section{A TEORIA DAS SITUAÇÕES JURÍDICAS PROCESSUAIS DE JAMES GOLDSCHMIDT}

A reflexão de Gregorio Robles quanto à ação me remeteu à teoria de James Goldschmidt, responsável por acender uma tênue chama, na tentativa de melhor iluminar esse tema, antes mesmo dos anos trinta do século passado ${ }^{8}$, ao defender que os direitos e obrigações, inerentes à ideia de relação jurídica, deveriam ser substituídos, no âmbito do processo judicial, pelas expectativas, possibilidades, ônus e afastamento do ônus, integrantes de uma situação de direito.

Assim, ao invés de relação jurídica, ter-se-ia no processo uma situação jurídica ${ }^{9}$, a viabilizar a compreensão segundo a qual determinada decisão judicial poderia afetar alguém que não faz parte da ação, algo indefensável ante a hipótese de se restringir o fenômeno do processo judicial a uma simples relação jurídica com direitos, deveres e sujeitos da relação, sempre integrados pelo elo formador daquela situação.

Efetivamente, Goldschmidt, em rasgo de avançada percepção quanto aos rumos do Direito Processual, passou a defender que os vínculos jurídicos que nascem no processo judicial, em relação aos envolvidos no litígio, não são propriamente relações jurídicas (consideração estática do direito), isto é, não são faculdades nem deveres no sentido de poderes sobre imperativos ou ordens, e sim situações jurídicas (consideração dinâmica do Direito), envolvendo expectativas quanto à posição jurisdicional a ser firmada e, em último caso, da futura coisa julgada; "en una palabra: expectativas, posibilidades y cargas. Sólo aquéllas son derechos en sentido procesal - el mismo derecho a la tutela jurídica (acción procesal) no es, desde este punto de vista, más que una expectativa jurídicamente fundada -, y las últimas - las cargas -, 'imperativos del proprio interés', ocupan en el proceso el lugar de las obligaciones" ${ }^{\prime 10}$.

\footnotetext{
${ }^{8}$ Derecho Procesal Civil. Traducción de la segunda edición alemana, y del Código Procesal Civil alemán, incluído como apéndice, por Leonardo Prieto Castro. Con adiciones sobre la doctrina y legislación española por Niceto Alcalá-Zamora Castillo. Barcelona: Editorial Labor, 1936.

${ }^{9}$ A situação jurídica foi incorporada à ciência processual como categoria graças a Kohler, conforme esclarece Niceto Alcalá-Zamora y Castillo eu sua advertencia preliminar ao livro de Goldschmidt (p. VII). O próprio Goldschmidt reconhece que "el concepto de la 'situación jurídica' se debe a KOHLER, el cual ve en ella una relación jurídica imperfecta”. Ob. cit., p. 8.

${ }^{10}$ Ob. cit., p. 8 .
} 
É possível identificar traços de sintonia entre essas duas perspectivas a respeito da complexidade que se apresenta no processo judicial.

Goldschmidt enfatiza que não se pode falar simplesmente em relação jurídica quanto às diversas atividades que se desenvolvem no litígio perante o Poder Judiciário.

Robles acentua que a ação judicial não se limita à abertura de um processo pelo interessado, uma vez que, embora a ação processual seja um mecanismo que inicia um processo perante um órgão jurisdicional, e por isso mesmo ela se caracteriza como ação jurídica, ainda assim existem muitas ações no processo que não se enquadram no conceito de ação processual ${ }^{11}$, e lamenta que "La terminología procesalista restringe demasiado el concepto de acción, e introduce con ello una cierta confusión conceptual" $" 12$.

\section{A FALTA DE UMA TEORIA GERAL DA AÇÃO NO DIREITO}

A propósito, é interessante verificar que, conforme destaca Hans Joas, professor de sociologia da Universidade de Freiburg (Alemanha), a ação “(...) es hoy en día concepto clave en la filosofía y en la mayor parte de las ciencias sociales y culturales; los esfuerzos en elaborar una teoría de la acción se encuentram en el punto neurálgico de los intereses teóricos actuales en todas estas especialidades" ${ }^{13}$, daí as diversas teorias com distintas versões, sendo as mais conhecidas as de Parsons (estrutura da ação social), Habermas (teoria da ação comunicativa), Gidens (teoria da estruturação), Castoriadis e Touraine (criatividade e inovação como versão da filosofia prática aristotélica) e Bernstein (caráter ativo do ser humano visto pelo pragmatismo) ${ }^{14}$. Quanto à Ciência do Direito, Gregorio Robles adverte que "la acción constituye un elemento

\footnotetext{
11 “(...) en el Derecho procesal el término acción tiene um significado muy específico, que viene de los romanos. La acción procesal es el mecanismo que inicia un proceso ante un órgano jurisdiccional. No cabe duda de que la acción procesal es una acción jurídica, pero hay otras muchas acciones en el proceso que no son 'acciones procesales". Teoría del Derecho - Fundamentos de Teoría Comunicacional del Derecho. Volumen I. Quinta edición. Madrid: Editorial Civitas, 2013. p. 266.

${ }^{12}$ Teoría del Derecho, p. 266.

${ }^{13}$ La Creatividad de la Acción. Traducción de Ignacio Sánchez de la Yncera con la colaboración de Pedro Cordero Quiñones. Madrid: Centro de Investigaciones Sociológicas, 2013. p. 59.

${ }^{14}$ Ob. cit., p. 60 e seguintes.
} 
central en el Derecho ${ }^{15}$, e apesar disso "falta una auténtica teoría general de la acción en el Derecho"16.

Essa incongruência - a falta de uma teoria geral da ação no Direito, apesar da importância do tema para a própria compreensão de diversos fenômenos jurídicos -, parece ter contribuído para o descuido no estudo da ação no Direito Processual, simplificando-se por demais esse fenômeno, na medida em que se estabeleceu a conexão do conceito de ação com o momento da interposição da postulação no plano jurisdicional. E é justamente para essa redução de conceito, que Robles chama a atenção.

\section{A TEORIA COMUNICACIONAL DO DIREITO DE GREGORIO ROBLES}

A fim de que se possa assimilar a importância desse raciocínio, convém esclarecer que é importante fixar como premissa ou suporte teórico a estrutura de pensamento firmada por Gregorio Robles em sua Teoria Comunicacional do Direito, que é a da compreensão do Direito como um sistema comunicativo ou de signos, com características peculiares. Para ele, o sistema a servir de base para tal linha teórica é o sistema jurídico, gerado pela dogmática, e que reflete o texto do ordenamento ${ }^{17}$.

E como consequência dessa opção teórica, todos os demais conceitos jurídicos formais precisam se adequar aos lugares correspondentes na teoria formal ou pura do Direito $^{18}$, e isso faz com que se coloque o tema da ação numa complexidade dentro do território do Direito Processual.

Pode-se dizer que Goldschmidt lançou fachos de luz no Direito Processual, ao afastar a simplória percepção de que um processo judicial se traduziria em simples relação jurídica. Todavia, naquela ocasião, ele não explicitou quais seriam essas relações possíveis, optando pelo conforto de atribuir ao fenômeno um conceito geral.

\footnotetext{
15 Teoría del Derecho, p. 265.

${ }^{16}$ Teoría del Derecho, p. 266.

17 Teoría del Derecho, p. 170.

18 "La Teoría comunicacional del Derecho se propone, como no podía ser de otra manera, situar adequadamente todos los conceptos jurídicos formales en el lugar que les corresponda dentro de la primera de sus partes que, como sabemos, es la teoría formal o pura del Derecho". Teoría del Derecho, p. 502.
} 
Isso é perfeitamente compreensível, diante da influência da doutrina civilista da época, que elegeu a categoria da situação jurídica para tentar justificar as peculiaridades que escapavam à tradicional estrutura das relações jurídicas ${ }^{19}$.

Nos tempos atuais, é possível esmiuçar essa complexidade, graças à sofisticada percepção de Gregorio Robles quanto aos fenômenos jurídicos, e aproveitando sua análise a respeito da relação jurídica como relação comunicacional.

A ação tanto pode ser uma situação jurídica (aspecto abstrato) como uma relação jurídica (aspecto concreto), e nesse último caso a proposta de Robles é a de centrar três tipos de relações jurídicas básicas: "las relaciones entre sujetos jurídicos o relaciones interpersonales o intersubjetivas, las relaciones entre ordenamientos o relaciones inersistémicas y las relaciones entre el Derecho y otros órdenes normativos como la moral, los usos sociales y la religión, o sea, las relaciones interordinales"20.

Em sintonia com essas premissas, parece-me adequado afirmar que, no Direito Processual, considerando cada fase de desenvolvimento das diversas relações jurídicas que surgem no processo - notadamente as intersubjetivas -, a ação adquire novas e diferentes texturas na roupagem da jurisdição, a depender da necessidade que se impõe para a materialização de direitos, deveres e ônus, nesse caminho desenvolvido na trajetória do processo.

Essa luminosa mirada nos leva à compreensão de algumas doutrinas avançadas no âmbito do Direito Processual brasileiro, mas que na época de suas afirmações não encontraram a devida ressonância, justamente pela falta de percepção da existência das diversas relações jurídicas decorrentes da ação, como é o caso das avançadas ideias defendidas no Brasil por Pontes de Miranda, ainda nos anos 1970, ao sustentar que, ao se propor uma ação, forma-se uma relação jurídica processual entre o autor da ação e o juiz; após se chamar o réu para integrar o processo, tem-se o aperfeiçoamento da relação jurídica, mas ela já existia antes mesmo de tal ato ${ }^{21}$.

\footnotetext{
${ }^{19}$ Gregorio Robles chama a atenção para o fato de que, "en la doctrina civilista el concepto de situación jurídica se ha elaborado sobre todo para entender determinadas situaciones jurídicas más bien peculiares" (Teoría del Derecho, p. 500), de modo que "La situación jurídica se convierte de esta manera en um concepto auténticamente general, aplicable a todos los componentes de un ámbito jurídico". Ob. cit., p. 523.

${ }^{20}$ Teoría del Derecho, p. 567.

${ }^{21}$ Tratado das Ações. Tomo I - Ação, Classificação e Eficácia. São Paulo: Revista dos Tribunais, 1970.
} 
Pontes de Miranda teve o cuidado de pensar a ação no processo como algo que trazia diversos efeitos, inclusive o de estabelecer a eficácia da futura decisão judicial, no que ele denominava de "energia automática da resolução judicial"22, eis que, "[q]uando se propõe uma ação, qualquer que seja, exerce-se a pretensão pré-processual, que é a pretensão à tutela jurídica, pois o Estado, desde que se estabeleceu o monopólio estatal da Justiça, a essa tutela se vinculou, e exerce-se, com o remédio jurídico processual adequado, a ação de direito material. Às vezes se chama ação ao remédio jurídico processual (e.g., ação ordinária, ação sumária), o que leva a equívocos, devido à ambiguidade. A ação é classificada conforme aquilo que se espera da sentença, se a ação for julgada procedente. Se de força eficacial declarativa a sentença que se espera, declarativa chama-se a ação. Se constitutiva a eficácia da sentença que se espera, constitutiva chama-se a ação. Se condenatória, mandamental, ou executiva a sentença que se espera, condenatória, mandamental, ou executiva diz-se a ação" ${ }^{23}$.

Conclui então Pontes de Miranda que "[a] preocupação da ciência do direito até há pouco [a obra é de 1970] foi a de conceituar as ações e classificá-las como se cada uma delas só tivesse uma eficácia: uma fosse declarativa; outra, constitutiva; outra, condenatória; outra, mandamental; outra, executiva. (...) Não há nenhuma ação, nenhuma sentença, que seja pura. Nenhuma é somente declarativa. Nenhuma é somente constitutiva. Nenhuma é somente condenatória. Nenhuma é somente mandamental. Nenhuma é somente executiva. A ação somente é declarativa porque a sua eficácia maior é a de declarar. Ação declaratória é a ação predominantemente declaratória. Mais se quer que se declare do que se mande, do que se constitua, do que se condene, do que se execute" 24 .

Eis a complexidade das relações jurídicas decorrentes da ação, em doutrina por demais adiantada no tempo para o momento vivenciado pelo Direito Processual brasileiro, onde se adotava àquela época - e com inacreditável persistência mesmo nos dias de hoje - a visão restrita da ação, identificando-a com o momento da postulação. Essa classificação das ações tendo como referência o fenômeno da eficácia, adorna com

\footnotetext{
22 Ob. cit., p. 160.

${ }^{23}$ Idem, pp. 94/95.

${ }^{24}$ Ibidem, pp. 117 e 124.
} 
moldura de relevância o efeito da decisão judicial nas relações jurídicas intersubjetivas do processo.

Araken de Assis, além de destacar a importância dessa classificação das ações de Pontes de Miranda em suas cargas de eficácia, ainda desdobra os graus de eficácia sob a identificação de adjetivos que apontam a eficácia preponderante e as demais que gravitam em torno dos efeitos da decisão, denominando-as de eficácia principal, eficácia imediata, eficácia mediata e eficácia secundária, lembrando que “(...) nenhuma ação nasce pura. Ela representa um conjunto de eficácias, em que uma delas, localizada pela aspiração maior do autor, desponta como principal. Mas este feixe de eficácias se decompõe como a luz solar no espectro. Uma dessas eficácias, porque preponderante, decide a inclusão da sentença na classe adequada" 25 .

\section{A CONVERGENCIA DAS TEORIAS DE JAMES GOLDSCHMIDT E GREGORIO ROBLES}

Voltando a Robles, como toda relação jurídica é uma relação comunicacional ${ }^{26}$, é possível compreender que os múltiplos momentos que se estabelecem na ação no Direito Processual geram relações jurídicas diversas, a depender do elo comunicacional que se estabelece.

Assim, realizando a convergência das teorias de Goldschmidt e de Robles, explicitam-se, nos vários momentos da ação processual, as relações jurídicas correspondentes:

I) Antes do litígio - ao se pensar no uso de determinada ação processual (momento anterior ao litígio), esse seria o primeiro indicativo de definição das cargas de eficácia da futura e provável decisão judicial (expectativa de relação jurídica);

II) Início do litígio - no instante em que se realiza o ingresso da pretensão de direito material mediante o uso de uma ação processual (momento inicial), tal ato

\footnotetext{
${ }^{25}$ Execução Civil nos Juizados Especiais. 5. ed., revista e atualizada. São Paulo: Revista dos Tribunais, 2013 , p. 29.

${ }^{26}$ Teoría del Derecho, p. 574.
} 
instaura a primeira relação intersubjetiva, firmada entre o autor e o juiz (relação jurídica envolvendo o Estado);

III) Desenvolvimento do litígio - por ocasião do desenvolvimento daquela ação (percurso na trajetória do processo) surgem várias relações jurídicas, não somente as decorrentes dos deveres que se impõem ao juiz, como o de zelar pela imparcialidade, como também as relações jurídicas representadas por direitos e ônus às partes, a exemplo do direito de defesa e do ônus das custas processuais (relações jurídicas obrigacionais);

IV) Encerramento do litígio - a solução da ação mediante decisão judicial definitiva (momento de julgamento), estabelece um vínculo entre a decisão e a escolha inicial da ação (relação jurídica de vínculo entre a ação e sua eficácia).

\section{Conclusões}

Ao apontar quatro momentos da ação processual com seus elementos correspondentes, pode-se dizer que, com a convergência das teorias de Gregorio Robles e James Goldschimidt, é possível compreender melhor os diversos fenômenos processuais, como por exemplo, o da questão das cargas de eficácia das decisões judiciais, a limitação do juiz ao pedido, o vínculo de obrigatoriedade que se estabelece para terceiros que sequer participaram do processo judicial, e tantos outros aspectos que incidem no âmbito do processo.

A a doutrina tradicional não se preocupou muito em elucidar tais fenômenos a partir de perspectivas outras que não sejam a da simples estrutura do próprio processo, ou seja, enquadrando-os como consequência de um único instante do processo, qual seja, o da inauguração do litígio. Robles e Goldschmidt nos mostram que há muito mais a observar na dinâmica do processo.

Convém deixar registrado que essa tentativa de superar teorias até então firmadas ao longo da construção da doutrina processual não representa, em absoluto, o descarte da preciosa colaboração de tantos pensadores em busca da melhor compreensão do Direito. 
Ao contrário, há de se aceitar que o destino das ideias é justamente o de servir de base para futuras especulações que só se mostram possíveis exatamente por conta do alicerce construído por aqueles que, ao seu tempo, dispunham de uma óptica compatível com a sua época.

A crítica que se faz não representa um decreto de esquecimento quanto aos precursores do pensamento jurídico; é acima de tudo uma homenagem, pois a ultrapassagem de teorias pretéritas impõe seu prévio reconhecimento. Essa mudança de rota, contudo, é a trajetória natural nessa caminhada na larga estrada jurídica.

A título de exemplificação, sem a pioneira visão firmada no final do século XIX por Bülow quanto ao processo como relação jurídica que avança gradualmente e que se desenvolve passo a passo $^{27}$, e também se não fosse a percepção de Liebman no início dos anos 1950 ao defender a natureza dinâmica do direito processual civil, por regular um mecanismo jurídico em movimento ${ }^{28}$, dificilmente se construiriam teses ampliadoras dessas iniciais ressonâncias em busca da exata compreensão das relações jurídicas existentes no processo judicial.

$\mathrm{Na}$ atualidade, Gregorio Robles, ao efetuar seu elegante giro de perspectiva, chamou a atenção para um verdadeiro paradoxo que se instalou na doutrina processual, ao considerar a ação como um sentido de movimento somente para a instauração do processo, ou seja, no início do litígio judicial, quando o termo ação, por si só, carrega em sua estrutura de linguagem a dinâmica como traço identificador desse evento.

Desse modo, no Direito Processual, a ação deve gerar um deslocamento constante, ao invés de se perceber tal movimento somente quando de seu nascimento, conforme equivocadamente enfoca a doutrina processual em geral.

É preciso analisar cada momento da ação, para se chegar a conclusões diferenciadas, como se viu nos exemplos aqui destacados. Afinal, como ressaltam

\footnotetext{
${ }^{27}$ A obra Die Lehre von den Processeinreden un die Processvoraussetzungen, publicada em 1868, e traduzida para a língua espanhola com o título de La Teoría de las Excepciones Procesales y los Presupuestos Procesales, é tida como marco inicial da firmação do Direito Processual como ciência, no âmbito da Europa ocidental, e ali defende Oskar Von Bülow que "[e]l proceso es una relación jurídica que avanza gradualmente y que se desarrolla paso a paso". Traducción de Miguel Angel Rosas Lichtschein. Buenos Aires: Librería El Foro. p. 10.

28 "Il diritto processuale civile ha inoltre natura dinamica, perché regola un meccanismo giuridico in movimento". Manuale di Diritto Processuale Civile - Principi. Sesta Edizione. Milano: Giuffrè Editore, 2002. p. 35 .
} 
Francesco Viola e Giuseppe Zaccaria, interpretar é comportamento e produto $^{29}$; isso porque, conforme expressão firmada por Mathieu, o intérprete é um transportador de intenções ${ }^{30}$ ou, ainda no dizer de Viola e Zaccaria, a interpretação é a atividade que atribui significado a partir de determinado signo ${ }^{31}$. Digo mais: interpretar é percurso e ponto de chegada. É caminho e destino.

\section{REFERÊNCIAS:}

ASSIS, Araken de. Execução Civil nos Juizados Especiais. 5. ed., revista e atualizada. São Paulo: Revista dos Tribunais, 2013.

BÜLOW, Oskar Von. La Teoría de las Excepciones Procesales y los Presupuestos Procesales. Traducción de Miguel Angel Rosas Lichtschein. Buenos Aires: Librería El Foro.

GOLDSCHMIDT, James. Derecho Procesal Civil. Traducción de la segunda edición alemana, y del Código Procesal Civil alemán, incluído como apéndice, por Leonardo Prieto Castro. Con adiciones sobre la doctrina y legislación española por Niceto Alcalá-Zamora Castillo. Barcelona: Editorial Labor, 1936.

JOAS, Hans. La Creatividad de la Acción. Traducción de Ignacio Sánchez de la Yncera con la colaboración de Pedro Cordero Quiñones. Madrid: Centro de Investigaciones Sociológicas, 2013.

LIEBMAN, Enrico Tulio. Manuale di Diritto Processuale Civile - Principi. Sesta Edizione. Milano: Giuffrè Editore, 2002.

MACHADO, Fábio Cardoso; AMARAL, Guilherme Rizzo - (organizadores). Polêmica sobre a ação - a tutela jurisdicional na perspectiva das relações entre direito e processo. Porto Alegre: Livraria do Advogado. 2006.

\footnotetext{
29 'Da una parte 'intepretazione' indica l'attività di attribuzione di significato ad un documento, ad un'espressione linguistica, ad un comportamento umano: in questo senso essa è sinonimo di interpretare, desina cioè un atto o una serie di atti attraverso cui si esplica l'attività di interpretazione. Dall'altra parte 'interpretazione' si riferisce al risultato di tale attività, ao prodotto insomma dell'interpretare (...)". Diritto e Interpretazione - Lineamenti di Teoria Ermeneutica del Diritto. Roma: Editori Laterza, 1999. p. 111.

${ }^{30}$ Diritto e Interpretazione, p. 106.

31 "L'interpretazione può essere definita - approssimativamente e inizialmente - como quell'atività che coglie e atrribuisce significati a partire de determinati segni” (ob. cit., p. 106).
} 
Rio de Janeiro. Ano 16. Volume 23. Número 1. Janeiro a Abril de 2022

Periódico Quadrimestral da Pós-Graduação Stricto Sensu em Direito Processual da UERJ

Patrono: José Carlos Barbosa Moreira (in mem.). ISSN 1982-7636. pp. 930-944

www.redp.uerj.br

PONTES DE MIRANDA, Francisco Cavalcanti. Tratado das Ações. Tomo I - Ação,

Classificação e Eficácia. São Paulo: Revista dos Tribunais, 1970.

ROBLES, Gregorio. Teoría del Derecho - Fundamentos de Teoría Comunicacional del

Derecho. Volumen I. Quinta edición. Madrid: Editorial Civitas, 2013.

ZACCARIA, Giuseppe; VIOLA, Francesco. Diritto e Interpretazione - Lineamenti di

Teoria Ermeneutica del Diritto. Roma: Editori Laterza, 1999. 